\title{
MECHANICAL RELIABILITY
}


Macmillan title of related interest

David J. Smith, Reliability and Maintainability in Perspective (Second Edition) 


\section{MECHANICAL RELIABILITY}

A. D. S. CARTER

Second Edition

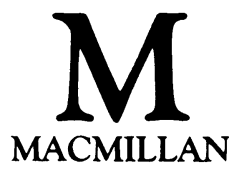


All rights reserved. No reproduction, copy or transmission of this publication may be made without written permission.

No paragraph of this publication may be reproduced, copied or transmitted save with written permission or in accordance with the provisions of the Copyright Act 1956 (as amended).

Any person who does any unauthorised act in relation to this publication may be liable to criminal prosecution and civil claims for damages.

First edition 1972

Second edition 1986

Published by

MACMILLAN EDUCATION LTD

Houndmills, Basingstoke, Hampshire RG21 2XS

and London

Companies and representatives

throughout the world

Typeset by TecSet Ltd,

Sutton, Surrey

British Library Cataloguing in Publication Data

Carter, A. D. S.

Mechanical reliability. -2 nd ed.

1. Reliability (Engineering)

I. Title

$620^{\prime} .00452$ TS173

ISBN 978-0-333-40587-1 ISBN 978-1-349-18478-1 (eBook)

DOI 10.1007/978-1-349-18478-1 
TO

HAZEL CARTER

IN MEMORIAM 


\section{Contents}

Preface to the first edition ix

Preface to the second edition $\quad \mathrm{x}$

Notation xii

Glossary $\quad$ XV

1 Introduction 1

2 Definitions 4

3 Probability as a measure of reliability 13

$\begin{array}{lll}3.1 & \text { Physical approach } & 13\end{array}$

3.2 Detailed mathematical analysis 33

4 The variation of reliability with time 39

$\begin{array}{lll}4.1 & \text { General physical approach } & 39\end{array}$

$\begin{array}{lll}4.2 & \text { Mathematical analysis } & 49\end{array}$

4.3 Mathematical treatment of rectangular distributions with tails 51

4.4 Variation of reliability with time for normally distributed $\begin{array}{ll}\text { loads and strengths } & 55\end{array}$

$\begin{array}{ll}4.5 & 59\end{array}$

$\begin{array}{lll}4.6 & \text { The non-intrinsically reliable item } & 73\end{array}$

$\begin{array}{lll}5 & \text { Wear-out } & \mathbf{7 8}\end{array}$

$\begin{array}{lll}5.1 & \text { General representation of the process } & 78\end{array}$

$\begin{array}{ll}5.2 \text { The simple wear-out process } & 80\end{array}$

$\begin{array}{lll}5.3 & \text { Wear-out by fatigue } & 85\end{array}$

5.4 A possible generalised approach to wear-out 106

$\begin{array}{ll}5.5 \text { The significance of wear-out } & 108\end{array}$

$\begin{array}{llr}6 & \text { Some statistical distributions } & 117\end{array}$

$\begin{array}{ll}6.1 \text { Scope of study } & 117\end{array}$

$\begin{array}{ll}6.2 \text { The normal distribution } & 118\end{array}$

$\begin{array}{ll}\text { 6.3 The exponential distribution } & 122\end{array}$ 
6.4 The Weibull distribution

6.4.1 General characteristics of the Weibull distribution $\quad 127$

6.4.2 Weibull analysis

6.4.3 Representation of failure patterns by Weibull distributions

6.4.4 Weibull analysis with drop-outs (or censored data)

6.4.5 The Weibull distribution for general data representation

6.4.6 The modified Weibull distribution

6.4.7 Evaluating the constants in the modified Weibull distribution

$\begin{array}{lll}6.5 & \text { The log-normal distribution } & 154\end{array}$

6.6 The Pareto distribution 157

7 Failures in the field 160

$\begin{array}{ll}7.1 \text { Quality of performance } & 160\end{array}$

$\begin{array}{ll}7.2 & \text { Field evidence } \\ & 162\end{array}$

$8 \quad$ An appraisal of component reliability 183

9 Maintenance 186

9.1 General introduction $\quad 186$

9.2 The mathematical model 189

9.3 Reliability with scheduled and unscheduled maintenance 192

9.4 On condition maintenance 209

9.5 Maintainability 221

9.6 Trade-off: reliability/maintainability 225

$\begin{array}{lll}9.7 & \text { Durability } 230\end{array}$

9.8 Review of maintenance aspects 237

10 Design for reliability 244

10.1 The design process 244

10.2 The requirement 245

10.3 The conventional design process 249

10.3.1 Design for stress-rupture phenomena 252

10.3.2 Design for fatigue 260

10.3.3 Some general notes on strength assessment 264

10.3.4 Checklists 266

10.3.5 Failure modes and effects analysis 275

10.3.6 Design or milestone reviews 296

10.3.7 Some concluding remarks on conventional design $\quad 297$

10.4 Development 298

10.5 Some final design considerations 329

11 System or equipment reliability 331

11.1 Introduction 331

11.2 The Reliability Block Diagram (RBD) 331 
viii CONTENTS

11.3 Reliability prediction

$\begin{array}{lll}11.4 & \text { Reliability apportionment } & 339\end{array}$

$\begin{array}{ll}11.5 \text { Parallel redundancy } & 340\end{array}$

11.6 An overview of system reliability 344

12 The role of the user in achieving reliability 346

12.1 The user/designer relationship

12.2 Collection and collation of user experience 347

13 Management aspects of reliability 354

14 Concluding remarks 365

15 Solutions to exercises $\quad 369$

Reading list

References $\quad 481$

Index 


\section{Preface to the first edition}

My attention was first drawn to problems of mechanical reliability in the early sixties by my wife's utter disgust at the behaviour of items of everyday use which a simple engineering assessment soon showed to be woefully inadequate. This led to a more professional appraisal of the situation and of some of the problems involved. Although there was a great deal of information on the reliability of electrical and electronic equipment and the accompanying mathematical theory, very little had been written from the point of view of the mechanical engineer. The essential difference between mechanical and electrical behaviour and the much wider issues involved in mechanical reliability seemed to be ignored in standard texts, though a number of specialist studies were available. The need for a balanced integrated account of the subject was obvious even at that stage. From everyday items my interest naturally turned to Service equipment. As a result of these studies an attempt was made to introduce some of the concepts of mechanical reliability, albeit on a small scale, into some of my specialist courses as long ago as 1965. In 1970 I was able to introduce a course of lectures into the first degree at RMCS. In general I have found students very keen to come to grips with the subject, which they find interesting, stimulating, and challenging, and also of real practical relevance and importance. This book has been based on my studies of the subject, and the experience gained in teaching over the last few years.

My knowledge and approach to the subject has been influenced by many friends and colleagues both in industry and the Services, and in the teaching world. In addition to the source material quoted in the references I must have unwittingly drawn on the experience of many who I cannot acknowledge in detail. In particular I am especially grateful for all the helpful comments I received on my original notes. It would be invidious to name a few out of the many, but special mention must be made of Frank Nixon for many helpful discussions and encouragement to publish this work. Finally, I would acknowledge detail assistance I have received from many colleagues including Mr A. J. Laurie in preparing many of the figures and $\mathrm{Mr}$ D. D. Appleford in acting as a willing guinea pig for most of the exercises.

A.D.S.C.

(Shrivenham, 1972) 


\section{Preface to the second edition}

A lot of water has flowed under the bridge since the first edition of this book was published, although to those of us directly concerned progress has often been disappointingly slow. However, ideas have developed significantly, and the time does seem just about right for a full re-appraisal of the subject matter presented in the earlier edition. In many ways this new edition is a complete rewrite of the earlier version, though the approach is exactly the same. The general format has been retained, and the exercises are still regarded as an integral part of the treatment, so the author's preferred solution (which, as typical of practical engineering problems, should never be regarded as the only one) is once again always given in full.

Throughout the book a number of detail changes have been made to improve clarity on the basis of past teaching and lecturing experience, but the significant changes can be summarised as follows. Apart from rather more emphasis on definitions, which teaching experience has shown to be necessary, the opening chapters remain essentially unchanged. The first substantive difference occurs in the treatment of random failures, which formed a large part of the first edition. This has been extended to include loading roughness. It is an important factor that had not been properly evaluated at the time the first edition was written, and no modern treatment of mechanical reliability would be complete without it. This leads to an appraisal of intrinsic reliability and similar concepts. The most significant difference between the two editions would, however, be the treatment of wear-out failures. Treatment in the first edition was superficial, to say the least, and since this accounts for the vast majority of mechanical failures I have given it a much greater coverage. In particular fatigue, which is probably the most important mechanical failure mechanism having no counterpart in the electronic world, is studied in detail. The treatment of maintenance has had to be revised to line up with the new approach to wear-out failures, and I believe is thus much improved. The chapter on design required corresponding revision, though the general flavour remains much the same. In this chapter I have devoted rather more space to estimating factors of safety and to design for fatigue, as well as giving more specific examples of FMEA and FTA techniques than in the first edition. The chapter on development follows much more along the lines of the early edition, 
but with the addition of reliability growth evaluation techniques, which were in their infancy when the first edition was written and not then included. The chapter on management has been extended, and rounds off the treatment of the subject as before.

In one respect this edition remains exactly the same as the first: it is a book written about mechanical reliability for mechanical engineers; and although mathematical rigour has been called upon when necessary, an essentially practical engineering approach again has been followed throughout.

A.D.S.C.

(Oxford, 1985) 


\section{Notation}

$A$ availability, acquisition cost, constant used in the SIL equation

$a$ distance or length

$B$ constants used in cumulative costs and the SIL equations

$B_{x} \quad$ life to $x$ per cent cumulative failures

$b \quad$ distance or length

C cost, constant in SIL equation

$C_{\mathrm{c}} \quad$ cumulative cost

$\bar{C}_{\mathrm{c}} \quad$ mean cumulative cost

$C_{\mathrm{M}} \quad$ maintenance cost

$C_{\mathrm{m}} \quad$ mean cumulative maintenance cost

$C_{0} \quad$ basic running costs

$C_{R} \quad$ cost of equipment to achieve reliability $R$

$C_{\mathrm{s}} \quad$ scheduled maintenance cost

$C_{\mathrm{u}} \quad$ unscheduled maintenance cost

c constant defined in various contexts

D durability

$d \quad$ diameter, damage due to fatigue

E Young's modulus

$E(s)$ probability density function of endurance (fatigue limit)

$\boldsymbol{e} \quad$ exponential function

$F \quad$ probability of failure, that is, cumulative failures

$F(x) \quad$ cumulative failures in terms of variable $x$

$f \quad$ frequency of vibration

$f(x)$ probability density function of failure in terms of variable $x$

$g \quad$ acceleration due to gravity

$h \quad$ small time interval

$h_{\mathrm{L}} \quad$ constant value of load probability density function (rectangular distribution)

$h_{\mathrm{s}} \quad$ constant value of strength probability density function (rectangular distribution)

I initial cost

$i \quad$ order number of successive events 
$j \quad$ order number of successive events

$K \quad$ cost ratio of unscheduled to scheduled maintenance

$K_{1,2,3} \quad$ constants defined in text

$k \quad$ constants defined in text

$L \quad$ load

$\bar{L} \quad$ mean load or sometimes nominal load

$L_{\mathrm{s}} \quad$ load causing failure in single application after fatigue damage

$L_{\mathbf{i}} \quad$ successive loads in fatigue load cycle

$L(s) \quad$ probability density function of occurrence of load

$M \quad$ maintainability

$M_{x} \quad$ maintainability for specified value of variate $x$

MTBF mean time between failures

MTBO mean time between overhauls

MTR mean time to repair

MTTF mean time to failure

$m$ mean time between failures, slope of linear curves

$N, n$ number (of components, cycles, etc.)

$N_{i} \quad$ number of fatigue cycles to failure at loads $L_{i}$

$N_{\mathrm{s}} \quad$ number of fatigue cycles to failure at load $L_{\mathrm{s}}$

$N(s) \quad$ function giving fatigue $s-N$ curve

$n_{i} \quad$ number of cycles at load $L_{i}$

$P, p \quad$ probability

$q \quad$ probability

$R \quad$ probability of success $=$ reliability

$R(t) \quad$ reliability expressed as a function of time

$r(t) \quad$ repair limit cost

$S \quad$ strength

$\bar{S} \quad$ mean strength

$S(s) \quad$ probability density function of occurrence of strength

$s \quad$ stress

$s_{\mathrm{f}} \quad$ fatigue stress of an individual item

$T \quad$ time for, or between, specific events

$t \quad$ time as a general variable

$t_{\mathrm{c}} \quad$ locating constant in modified Weibull distribution

$t_{0} \quad$ locating constant in Weibull and other distributions

$V \quad$ volume

$X, Y \quad$ Cartesian coordinates

$x \quad$ arbitrary variable

$\alpha \quad$ log-normal dispersion, Duane growth parameter

$\beta \quad$ Weibull shaping parameter

$\Gamma \quad$ Gamma function

$\Delta x \quad$ small increment in any variable $x$

$\eta \quad$ Weibull scaling parameter (characteristic life)

$\lambda$ failure rate 
$\lambda(t)$ failure rate expressed as a function of time

$\rho$ density

$\sigma \quad$ standard deviation

$\tau \quad$ time

\section{Suffixes}

$1,2,3 \ldots$ successive values of series of events, items, components, etc.

L refers to load

0 a particular value of

$\mathrm{S} \quad$ refers to strength

s scheduled

u unscheduled

$n \quad$ a combination of $n$ items 


\section{Glossary}

Availability. The probability that an item, at any instant in time, will be available. Available. The state of an item such that it can perform its function under stated conditions of use and maintenance in the required location.

$B$-percentile Life. The length of time at which a stated proportion ( $B$ per cent) of a sample of items has failed.

Conditional Failure Rate. A more precise description for failure rate - see Failure Rate.

Cumulative Failure Rate. Total failures divided by total equipment operating time.

Defect. Any non-conformance of an item with its specifications and drawings.

Durability. The ability to resist the adverse effects of environment, use, and maintenance with the progress of time.

Early Life Failures. Failures which occur in the weaker members of a population during the early life period.

Failure. Any defect which results in the inability of the item to perform its specified functions.

Failure Rate. The rate at which failures arise in a given non-maintained population expressed as a proportion of the survivors. It is defined mathematically by equation (2.5).

Failure-inducing Load. The particular load, possibly of many, that causes failures. FMEA. Failure Modes and Effects Analysis.

FTA. Fault Tree Analysis.

Hazard or Hazard Rate. An alternative phraseology for failure rate.

Inherent Availability. Availability based on active repair time.

Instantaneous Failure Rate. A more precise phraseology for failure rate - see Failure Rate.

Maintainability. The ability to retain an item in, or restore it to, specification under the stated conditions of maintenance. It may be measured as the probability to achieve the objective within a stated time period, or as the time to achieve the objective for a given proportion of the population.

$M A R T$. Mean Active Repair Time.

$M D T$. Mean Down Time.

$M T B D$. Mean Time Between Defects. 
$M T B F$. Mean Time Between Failures. [Note that some variants, such as MDBF (Mean Distance Between Failures) etc. are often used.]

$M T T F$. Mean Time To Failure.

$M T T R$. Mean Time To Repair.

Occurrence of Failures. The rate at which failures arise in a changing (for example, maintained) population.

On Condition Maintenance. Maintenance carried out before an item fails, but only when its condition, established by continuous monitoring, indicates that failure is imminent.

Preventive or Scheduled Maintenance. Maintenance carried out to keep an equipment in satisfactory operational conditions by providing systematic replacement of components before they are expected to fail.

Random Failures. Failures which arise on a random basis, characterised by a constant failure rate.

Reliability. The ability of an item to perform a required function under stated conditions of use and maintenance for a stated period of time. It may be measured as a probability of success at any time, or the time for which a level of success can be assured.

Reliability Growth. The increase of reliability which occurs during development.

Repair Limit. The condition in which it is no longer economic to continue maintaining an item.

Repair Maintenance. Maintenance carried out on a non-scheduled basis to restore an item to a satisfactory condition by providing correction of a failure after it has occurred.

Scheduled Maintenance. See Preventive or Scheduled Maintenance.

Stochastic. Pertaining to a conjecture (OED), that is, lacking precise definition; involving a probability.

Stress. Force/area.

Wear-out Failures. Failures which are due to loss of strength with time or use. Whole (or Total) Life Costs. The total cost of possessing and using an equipment - comprising initial, maintenance, and operational costs such as fuel, staff etc., interest payable on capital, and so on - over its life span. 